\title{
La memoria del agua: el agua es río y el río es memoria
}

\section{The memory of water: water is river and the river is memory}

\author{
Sofía Astelarra* \\ Instituto de Investigaciones "Gino Germani", \\ Universidad de Buenos Aires / CONICET \\ sofiastelarra@gmail.com
}

* Prof. y Lic. en Sociología, Doctora en Ciencias Sociales por la Universidad de Buenos Aires. Jefa de Trabajos práctico en Fundamentos de Ecología Política, cátedra Dr. Domínguez, Fac. de Ciencias Sociales, UBA. Y profesora Titular en Gestión Ambiental y Desarrollo Sustentable; Ingeniería, Ciudad y Ambiente, UTN. F.R.General Pacheco. Investiga los modos de vida y procesos de avance del desarrollo inmobiliario-financiero, las transformaciones y las conflictividades sociales, ambientales y territoriales en los humedales deltáicos en las últimas décadas. Integra el Grupo de Ecología Política, comunidades y derechos del Instituto Gino Germani, UBA. Y el Observatorio de Humedales Delta. 


\section{Resumen}

El "río es memoria" escribió Haroldo Conti en su novela "Sudeste". Metáfora conmovedora dado que nos sugiere pensar de otro modo y abre preguntas epistemológicas: ¿es posible hacer una memoria del río?, ¿cómo cartografiar esa memoria? Indudablemente esta metáfora nos remite a la relación humanidad-naturaleza en un tiempo-espacio, en este caso las modalidades de relación históricas de las sociedades con "el río".

A partir de esta metáfora y sus implicancias, este trabajo pretende rastrear esa historia del presente de los ríos en el Bajo Delta del Paraná. Partimos del campo de la ecología política lationamericana, con un abordaje cualitativo retomando las voces de las personas que habitan el Bajo delta del Paraná, interrogando en sus modalidades de apropiación y significación en torno al río.

Palabras clave: .Ríos; Articulaciòn humanidad-naturaleza; Significaciones sociales; Sujetos; Bajo delta del Paranái

\section{Abstract}

The "river is memory" wrote Haroldo Conti in his novel Sudeste. It is a moving metaphor since it suggests us to think differently and opens epistemological questions. Is it possible to make a memory of the river? How can you map this memory? This metaphor undoubtedly reminds us of the human-nature relationship in time-space and in this case the modalities of the historical societal relationship with "the river."

Starting with this metaphor and its implications, this work aims to trace the present history of the rivers on the Under the Delta of the Paraná. We start from the field of political ecology with a qualitative approach, listening to the voices of the people who inhabit the lower Parana delta. We question their modalities of appropriation and significance when it comes to the river.

Key words: Rivers; Articulation humanity-nature; Social significations; Subjects; Lower Parana delta. 


\section{Introducción}

En este trabajo propongo interrogar respecto a la posibilidad de cartografiar la memoria del agua en tanto elemento fundamental que compone al/los ríos y que define la estructura ecosistémica de los humedales. A la vez que cartografiar al agua en la memoria o al "río en la memoria" en términos de la experiencia histórica sedimentada en significados, percepciones, afectos, modos de uso y manejo que hacen del río quienes lo habitan cotidianamente.

La inspiración de este interrogante surge, en parte, de la novela "Sudeste" de Haroldo Conti1 donde escribe el "río es memoria", una metáfora potente para pensar el presente del río al que refiere. Por otra parte, de mí trabajo investigativo y vital en el Bajo Delta del Paraná a partir del cual surge la necesidad de explorar esa metáfora que conjura a pensar de otro modo. Conti ha logrado traducir y recrear algunos escenarios isleños, sus personajes, historias, modos de vida y la turbulenta relación con el río, el monte $\mathrm{o}$, como conceptualizamos actualmente, los humedales. En ese desafío me he embarcado: reflexionar esa relación.

El desplazamiento a la memoria del agua tiene que ver con que este elemento natural es la condición de existencia de los humedales, en otras palabras, la estructura y funciones ecosistémicas de éstos depende de estar saturados de agua durante períodos recurrentes o en algún momento del año (Kalesnik y Quintana, 2006). Los humedales no son del todo acuáticos ni terrestres suelen presentar gran variabilidad en el tiempo como en el espacio, así los ciclos hidrogeológicos pueden implicar períodos de grandes sequías o inundaciones. Son ecosistemas heterogéneos que cumplen funciones ecológicas primordiales para la vida planetaria (regular el flujo hidrológico, recargar acuíferos, aporte de sedimentos, etc.), fuente de agua dulce, albergan gran biodiversidad ya que los seres vivos que lo habitan están adaptados (Kalesnik y Quintana 2006). En las últimas décadas vienen siendo revalorizados y resignificados en el contexto de cambio climático y "escasez de agua", aunque, principalmente, a partir de la intensificación de diferentes conflictos eco-territoriales por su apropiación y resignificación (Astelarra, 2014, 2016).

En este trabajo tomaré como caso de análisis la memoria del agua o de los ríos del humedal del Bajo Delta del

1. Haroldo Conti, escritor argentino desaparecido en la última dictadura militar de 1976.
Paraná (Kalesnik y Quintana, 2006)2, donde más de 350 ríos y arroyos constituyen, dan forma y contornean las islas. Esta zona, respecto al delta en su conjunto, tiene características singulares: en términos ecológicos desemboca en el estuario del Río de La Plata y se constituye como la zona de frente de avance (Kandus, 1997); en términos históricos, la forma de vida es similar a otros lugares deltáicos pero al estar próxima a la Ciudad de Buenos Aires y su área metropolitana se configuran otras dinámicas socio-histórico-ecológicas que requieren ser indagadas.

De allí que la metáfora "el río es memoria" me resulte potente para comprender esas singularidades y procesos actuales. En principio, propongo abrir algunos interrogantes que esta metáfora me sugiere, sin pretender agotar las reflexiones y análisis que suscita. Algunas son: ¿es posible hacer una memoria del río?, ¿qué significa que el río sea memoria?, ¿cómo cartografiar esa memoria?

Estas interrogaciones nos posibilitan comprender las relaciones históricas de las sociedades con el río o, en otro nivel analítico, la relación humanidad-naturaleza. Desde el campo de la ecología política latinoamericana abordamos ese vínculo a partir de la configuración de las relaciones de poder históricas en torno a la naturaleza, buscando construir una mirada crítica antiescencialista, que dé cuenta de las tensiones, transformaciones y reinvenciones del mismo a la vez que visibilizando sujetos, culturas, saberes, sentires, prácticas y discursos que han sido silenciadas/invisibilizadas por la episteme moderna-colonial-patriarcal (Escobar, 1999; Leff, 2006; Alimonda 2011).

Retomando el giro decolonial, Alimonda nos propone repensar la geografía latinoamericana, la configuración de la matriz territorial colonial que ha conformado una naturaleza colonizada. En aquellos paisajes "prístinos", "descubiertos" cabe interrogar si no han sido resultado

2. Área que es el tramo final de la Cuenca hidrográfica del Plata: "compuesto por un triángulo geográfico que comprende los ríos Paraná de las Palmas, Carabelas, Paraná Miní y Paraná Guazú. Políticamente la jurisdicción del Delta comprende a dos provincias, Buenos Aires y Entre Ríos. El Delta bonaerense se encuentra a su vez dividido en seis secciones y depende cada una de ellas a los Partidos de Tigre, San Fernando, Escobar, Campana, Zárate, Baradero y San Pedro respectivamente. El delta entrerriano está dividido en siete secciones que dependen todas del Departamento de Gualeguaychú. En total comprende 900.000 hectáreas" (Fernández, 2002: 13). 
del habitar histórico de las culturas que, al haber sido expulsadas y despojadas se ha invisibilizado su paso por estos lugares o su coevolución (Alimonda, 2011). Nos propone la re-escritura de las narrativas-geografías locales, revalorizando las culturas, sus saberes, resistencias, la relación sociedad-naturaleza que han mantenido históricamente.

Escobar y Leff (retomando a Foucault y Haraway) señalan que la naturaleza está ya significada por la humanidad, no existe una "naturaleza natural", sin embargo existen procesos biogeofísicos prediscursivos y presociales que escapan/desbordan lo humano y que le son irreductibles (Leff, 2014). Entonces Escobar, propone entender este vínculo en tanto articulación entre la historia y lo biológico, ambas están mutuamente implicadas a través de prácticas y mediaciones culturales:

"cada articulación tiene su historia y especificidad y está relacionada a modos de percepción y experiencia, determinados por relaciones sociales, políticas, económicas y de conocimiento, y caracterizada por modos de uso del espacio, condiciones ecológicas y otras. La tarea de la ecología política será delimitar y caracterizar estos procesos de articulación." [A los que denomina "regímenes de naturaleza"] (Escobar, A. 1999: 281)

Esta articulación resalta el carácter entretejido, de "acomodación mutua" o de interacción de las dimensiones discursiva, material, social, cultural, biofísica y política de la relación humanidad-naturaleza (Escobar, 1999). La apuesta es dar cuenta de esta articulación de manera no esencialista ni totalizante, indagando su complejidad y multiplicidad, entenderla no como estructura estática sino en tanto movimiento dinámico, continuo y conflictivo. Para ello es menester visibilizar los modos de conocer, de usar el espacio/territorio/naturaleza de las comunidades (locales, rurales, urbanas, etc.), de sentirla, percibirla, nombrarla y significarla a lo largo del tiempo, dentro del campo de las relaciones de poder y la configuración de los conflictos por establecer/imponer/construir ciertas modalidades de esa relación.

Para ello Leff propone la construcción de un diálogo de saberes y una política de la diferencia, en la cual se recuperan, revaloricen las experiencias históricas de las comunidades, así como las apuestas locales-emergentes presentes no como realidades pasadas o cuantitativamente irrelevantes, sino como apuestas vitales que expanden el futuro posible y el pensamiento, reinventando el presente y dicha articulación (Leff, 2006, 2014).

A partir de estos posicionamientos e interrogantes exploraremos la metáfora "el río es memoria". Me centraré en la memoria del presente, en las apropiaciones y significaciones en torno al río de quienes habitan el Bajo delta del Paraná, también menciono otros fragmentos textuales que han colaborado en construirlas.

En este sentido la interrogación respecto a cartografiar una memoria del agua o el río implica visibilizar sentidos, experiencias, prácticas y, por lo tanto, sujetos que han sido invisibilizados y producidos como ausentes en las narrativas dominantes, dando cuenta de la relación que han construido con éste, los modos de intervenirlo y la manera en la que el río ha condicionado o marcado su vida. Articulación o modalidad que se encarna, se hace cuerpo, va configurando un modo de subjetivación, una experiencia isleña vinculada intrínsecamente a esa relación del sujeto en la naturaleza y a la vez que la naturaleza en el sujeto. Indagar en las maneras de ser y hacer con/en la naturaleza en el presente es necesario para dar cuenta de la modalidad histórica de esa articulación: la memoria del río y el río en la memoria.

\section{La memoria del río.}

"La verdad es que las islas han sido por tradición reputadas hasta hoy inhabitables, y mil consejos ridículos mantienen todavía esta creencia. Cuéntase de un francés que, enamorado de las plantaciones de un carapachayo, hubo de comprarle su isla; y de regreso a Francia, despachó a su hijo con una colonia de obreros. Mas la nave surcó en vano el río, recorrió con la carta los lugares, sin encontrar la isla encantada, que había desaparecido por las creces del Paraná." (Domingo Faustino Sarmiento [1857], 2011: 59)

En aquellos iniciales escritos de viajeros, colonizadores e intelectuales, durante el primer período de colonización del Delta en los siglos XVI-XIX (Galafasi, 2005), la relación con el río responde a una perspectiva naturalista-moderna, que resalta las características idílicas, "paradisíacas", incluso románticas y bucólicas de éste y el delta en el cual "vierten sus aguas". El flujo del agua del río no encontraba obstáculos, sus cauces variaban de acuerdo a la dinámica ecosistémica generando "catástrofes" o 
"desapariciones" cada cierto periodo y quienes lo habitaban se adaptaban resignadamente. El río aparecía como un ente "caprichoso" pero "generoso" al proveer de peces por doquier y garantizar la fertilidad, exuberancia y abundancia de las tierras (tanto para el desarrollo productivo como su disponibilidad). Estas imágenes de la naturaleza van acompañadas de su reverso catastrófico, abominable u hostil: la desaparición de islas, personas, animales. Significaciones que han ido sedimentando hasta el presente tanto de quienes miran/escriben desde fuera las islas, como de la propia experiencia de quienes la habitan y las imágenes a las cuales el desarrollo inmobiliario evoca para el marketing de ventas.

Hasta hoy en día, lo interesante e incluso atrapante para escritores, artistas e investigadoras es que el funcionamiento ecosistémico es dinámico y mutable: los ríos y sus cauces varían con los años de acuerdo a "las creces", "crecidas y bajantes". O bien, desde la ecología podemos decir de acuerdo al régimen hidrológico de inundaciones y sequías, cuyo flujo de agua es fundamental para el proceso constante de formación y transformación de islas:

"Las más grandes aparecen atravesadas por arroyos, aguajes y zanjas. En algunos casos, estos cursos de agua cortan el terreno en dos, tres y hasta cinco porciones. Los cartógrafos, desalentados, han renunciado a organizar semejante división, negándose a bautizar cada terrón por separado: he aquí el motivo de que pocas islas posean nombre propio... Asimismo, las denominaciones que figuran en los mapas a menudo no hacen más que distinguir, genéricamente, a un vasto conjunto de islas e islotes. [...] El río al que los guaraníes Ilamaron Padre del Mar modela las costas, agregando materia en una banda y arrancándola en la opuesta, mientras, en algunos puntos del cauce, genera acúmulos que en un futuro no muy lejano serán islotes. Algunos crecerán hasta merecer el rótulo de islas, y el consecuente asentamiento de personas. Otros pueden permanecer casi en embrión: todo según los caprichos de la corriente y de los vientos. Muchos islotes no poseen sino unos diez metros cuadrados de superficie" (Muscillo, 2016: 1).

Los ríos colaboran con el proceso de formación/transformación de islas e islotes, funcionan en conjunto. Si revi- samos históricamente, Sarmiento y Marcos Sastre3 fueron precursores en describir estos procesos singulares del delta. Desde entonces, el "delta"se ha considerado por un lado, como un conjunto de islotes surcados por ríos, arroyos, aguajes, canales y zanjas; por otro, las islas en formación y las costas de los ríos como "pajonales", "yuyales", "bañados". Éstas últimas han sido "reputadas hasta hoy inhabitables" o bien "inhóspitas", "marginales". Estas imágenes colaboran en desvalorizar algunos ambientes del humedal e invisibilizan a sus habitantes.

Hace poco más de veinte años que estas zonas se denominan como humedales, Inés Malvárez (1999) fue la primera en definirlo dentro del ámbito de la biología/ ecología, contemporáneamente también las organizaciones ambientales locales. Será a partir del conflicto "Colony Park" que esta noción se instalará en la esfera pública y el escenario social resignificando las designaciones previas, visibilizando sujetos históricos a la vez que disputando las significaciones y apropiaciones del río y el delta (Astelarra, 2016).

Los ríos llevan impresos en sus nombres la memoria social. Paraná, Paraná Miní, Paicarabí, Carapachay, etc., atestiguan el habitar de las primeras comunidades originarias, los chanaes, chaná biguáes, carapachayos y guaraníes, lamentablemente tenemos escasos registros históricos escritos del modo de relacionarse de éstas con el río, resultado del proceso de colonización con su respectivo desplazamiento e invisibilización. Según Galafassi la gran mayoría de nombres se instituyeron en los tiempos de la primera colonización del delta (Galafassi, 2005).4 Desde entonces comenzaron a ser nombrados por las características o fisionomía del cauce:

3. Marcos Sastre ha escrito "El Tempe Argentino" una de las primeras obras en las que se describen las características del delta, tanto ecosistémicas, como de sus habitantes. Al igual que "El Carapachay" de Sarmiento o "Río abajo" de Liborio Justo, son los textos en los que podemos rastrear imágenes, significaciones, apropiaciones de quienes habitaban el río y el delta en su conjunto en la primera colonización.

4. Galafassi (2005) define tres modelos productivos y de apropiación de la naturaleza en el Delta bonaerense: 1) en los siglos XVIII-XIX, la colonización del Delta resultado de la inmigración europea y ocupación cuya relación con la incipiente Ciudad de Buenos Aires era proveer de carbón, leña, ser área de tránsito y contrabando; 2) de fines del siglo XIX a mediados del XX, el modelo frutihortícola asociado al poblamiento permanente, comienza el gran proceso de transformación del ecosistema "natural" al consolidarse el cultivo intensivo de frutales y hortalizas, se introduce el mimbre, la plantación de sauce y álamo, a la vez que, considerada área de recreación, deportes náuticos de sectores de altos ingresos y luego sectores populares con la instalación de recreos sindicales. En algunas de las entrevistas realizadas este momento se evoca como "la época de esplen- 
Arroyo Largo, Correntoso, La Espera y Esperita; Anguila. Asociado la fauna: Pacú, Dorado, Mojarra, La Nutria. O bien por el apellido del/a primer habitante tales como el arroyo Felipe, el Río Sarmiento o Albarracín. Incluso refieren a situaciones singulares como "Fulminante", que evoca al incendio de un buque de lujo de pasajeros a principios de siglo XX. En otros casos, refieren a leyendas, pestes, crímenes y milagros. A la vez que, a veces no sólo se nombra el río sino la isla o islote asociado a una familia. Por ello, es frecuente también que denominaciones de antiguas islas caigan hoy sobre pantanos o tierra firme ubicada muy lejos de antaño.

El arroyo "El Durazno" o "El Manzano" atestiguan la importancia de la producción de frutas y hortalizas que caracterizó el segundo modelo productivo asociado a la inmigración, colonización y ocupación permanente en las islas.

En los trabajos de campo, una de las entrevistadas, cuenta que en el arroyo Cruz del Gambado "todo era un vergel de frutas y flores. No sabes las casas que había en ese lugar". Este dejó de estar habitado hace más de 40 años al entrar en crisis el modelo fruti-hortícola, según Susana "el monte se fue devorando todo" $y$ "algunas personas de fin de semana hicieron lo suyo y se llevaron los pisos y cosas". En la actualidad se ha re nombrado como "Arroyo del vivero" porque, luego de la gran depresión de dicho modelo, supo funcionar un vivero hasta hace una década. Dado que la zona "se está volviendo a habitar por nuevos pobladores" que requieren coordenadas para transitar sus nuevos espacios de vida, también suelen Ilamarlo "Arroyo Leber" porque es el propietario del vivero y también dueño de una importante inmobiliaria

dor". 3) desde mediados a fines del siglo XX, por diversos factores económicos y ambientales se produce un proceso de crisis del modelo de producción frutihortícola, se instala el modelo forestal y se genera la emigración y depresión del delta. Finalmente, el último período va desde fines del siglo XX hasta la actualidad propongo denominarlo como "disputa por la reinvención del Delta". Sintéticamente, en las últimas décadas el Delta del Paraná viene siendo valorizado y resignificado como efecto de varios procesos que suceden simultánea y conflictivamente: por un lado, socialmente por ser un destino para vivir y cambiar de estilo o modo de vida urbano a uno rural o "en contacto con la naturaleza", o bien, porque mejora las condiciones de vida; por otro lado, ecológicamente dada su importancia ecosistémica por ser un humedal; por último, en términos de valorización económica por el incremento de, por un lado, las actividades productivas-industriales-extractivas (sectores forestal, agroindustrial, agroportuario y minero); por el otro, las actividades turísticas, urbanísticas y paisajística al ser un "entorno natural" cercano a la ciudad lo que le otorga un plus de valor económico para el sector inmobiliario-financiero principalmente. Procesos que vienen generando diferentes disputas o conflictos por la apropiación y significación del Delta (Astelarra, 2016). local. Estos "nuevos pobladores" no saben ni imaginan ese vergel que cuenta Susana, ni las "maravillosas casas y espectaculares muelles" que había ya que no han quedado huellas humanas, más que construcciones derruidas en medio de un imponente monte.

Así, coexisten las tres maneras de llamarlo, actualizando la práctica de nombrar-renombrar los arroyos y ríos a partir de una referencia de uso y conocimiento local. No sólo la fisonomía de las islas, o más bien el paisaje, sino también el modo de nombrar a los arroyos y canales va cambiando con los años de acuerdo a los usos del espacio y les habitantes, ${ }^{5}$ incluso en algunas ocasiones no coinciden los nombres que figuran en los planos con los que socialmente se usan. O bien en los mapas figuran arroyos que ya no existen dado que el proceso ecosistémico de sedimentación ha tapado su cauce volviéndolo intransitable o inexistente. Sin embargo, "los de toda la vida" 6 recuerdan esos nombres y sus variaciones y pueden usar uno $u$ otro indistintamente. He observado en situaciones cotidianas que en algunas ocasiones llaman a los arroyos o canales como se nombraban antaño como una manera de interrogar indirectamente hace cuánto tiempo se conoce la zona, o bien, como modo de investirse de cierta autoridad frente a quienes recién llegan a vivir en las islas.

El registro histórico de estas variaciones en los nombres, se conjuga con que a lo largo de la historia se van formando y transformando las islas, ya sea porque las personas han "abierto un canal" para comunicar un arroyo con un río principal, ya sea porque el ecosistema se caracteriza por ser dinámico de modo que la formación de islas es constante.

Respecto a la apertura de canales, hasta la década de los noventa, esta intervención sobre el ecosistema estaba en manos de les habitantes que "abrían a pala" ${ }^{7}$

\footnotetext{
5. Asumiendo que el lenguaje es una construcción social, pese a no estar aún abalado académicamente, pero sí siendo un tema actual de debate, he decido usar la "e" para designar e incorporar la diversidad de sexo-géneros

6. La autodenominación de "isleños de toda la vida" refiere a personas que ya son tercera o cuarta generación que habita las islas. Algunos se reconocen como "isleros" para diferenciarse de los "isleños" quienes serían recientemente mudados a vivir a las islas. Estos últimos también pueden reconocerse como "venidos". Utilizo esas nominaciones locales en los casos que es pertinente.

7. Si bien, puede referir a una pala de uso manual o una pala mecánica, maquinaria de pequeño porte que realiza movimientos de suelo en pequeña escala, esta expresión se utiliza principalmente para señalar la primera
} 
el nuevo curso de agua. "Los de toda la vida" rememoran casi heroicamente los momentos en que crearon un nuevo curso de agua, transformando su vida y la del resto. Esto respondía a la necesidad de transportar la producción (forestación, hortifruticultura, mimbre y junco) o al acceso a nuevos loteos populares para vivienda permanente. En otros casos, esos canales eran resultado de una intervención de obra pública como una política gubernamental para fomentar el desarrollo económico y el poblamiento permanente de las islas.

Frente a las características ecosistémicas de inundabilidad, se fueron generando diferentes técnicas locales de regulación del flujo del agua tanto para la producción como para demarcar los espacios vitales. Por un lado, los productores medianos y grandes realizaban -hasta la actualidad- endicamientos necesarios para la producción frutihortícola y luego la forestación en gran escala, esto requería inversión y disponibilidad de capital para las maquinarias. Práctica que genera impactos ambientales al interrumpir el flujo del agua y por ende el funcionamiento ecosistémico. Por otro lado, como práctica generalizada y en pequeña escala la realización de zanjas o sangrías -de 50 a $70 \mathrm{~cm}$ de profundidad- en el terreno para que el agua "drene" rápidamente luego de las crecidas o inundaciones, permitiendo la plantación de frutales, huertas para autoconsumo y la cría de animales. Las zanjas en general no llegan hasta el fondo de isla dejando el centro, donde está el pajonal, sin intervenir lo que permite el flujo del agua al ritmo ecosistémico. La realización de las zanjas no es tarea sencilla, si no están bien hechas se pueden desarmar con la afluencia del agua y lentamente vuelven a taparse. Esto mismo sucede con los canales artificiales, de manera que les isleñes han ido generando un saber en torno a las técnicas adaptadas al funcionamiento del ecosistema para lograr que el trabajo inicial no sea en vano. Saben que cada cierto tiempo es necesario "mantener"las zanjas "limpiándolas".

Así, los nombres y sentidos del río están imbricados en los usos y prácticas históricas que configuran una cultura e identidad local en función de éstos. A la vez que se van consolidando prácticas y conocimientos locales de regulación del flujo del agua de acuerdo a la adaptación a éste y la disponibilidad de tecnologías.

\section{El río en la memoria.}

"Sus hombres, los hombres de este río, este hombre que ahora observa las aguas con sus ojos de pez moribundo suspendidos sobre ellas como dos espejuelos suspendidos del aire, son en todo semejantes a él. Por eso todavía sobreviven. Por eso parecen tan viejos y lejanos y solitarios. No aman al río exactamente, sino que no pueden vivir sin él. Son tan lentos y constantes como el río. Y, sobre todo, son tan indiferentes como el río. Parecen entender que ellos forman parte de un todo inexorable que marcha animado por cierta fatalidad. Y no se rebelan por nada. Cuando el río destruye sus chozas y sus embarcaciones y hasta a ellos mismos. Por eso también parecen malos." (Conti, 1962)

La forma de vida o experiencia local no puede definirse como rural en un sentido clásico del término, ni urbana pese a que en los últimos años los procesos de urbanización han avanzado sobre las islas. La vida local se autodefine y la comprendemos como isleña:

"Silvana, si vos tuvieras que definir qué es el modo de vida isleño, ese que tanto hablás, ¿qué dirías? ¿hay un modo de vida isleño? ¿no hay? ¿qué es para vos?

Silvana: (Riéndose, mira al río) Y sí, qué se yo, la verdad que como dicen todos, que yo por ahí no le había prestado mucha atención porque está (hace un gesto con la mano como agarrándose el pecho) está tan arraigado a uno que no te das cuenta, indudablemente el modo de vida isleño está ligado al agua, acá es así. Lo primero que hacés cuando te levantás es ver el agua para cargar el tanque y ya pensás un montón de cosas si el agua está baja o alta. Si está alta, que te ande la bomba para cargar; que si está baja, si te va a parar la lancha; que si hay sudestada que tenés que subir todo arriba; o sea, siempre hacés la vida en función del agua, a pesar de que uno no necesita del río más que para movilizarse, en mí caso particular, no? Pero todo es el agua. [...]Todo es el agua, en la vida personal como el trabajo, en el mío en particular, influye totalmente [en las escuelas]. Y después qué se yo, como uno se cría con el agua, vas desarrollando diferentes cosas, actitudes diarias que no te das cuenta pero que tienen que ver con eso. No sé la verdad que mucho yo no te sé decir, porque uno lo tiene tan tan arraigada que no sé qué decirte. [...]

Para todo, para navegar, tenés que saber agarrar una ola, yo pensaba lo que te pasó a vos que te mojaste, si te 
tenés que mojar, te tenés que mojar, igual que si te tenés que dar vuelta, te tenés que dar vuelta. Pero hay unas técnicas o sea tendríamos que andar [navegar] entonces yo te digo." (Silvana, 2013)

En su relato, por un lado, da cuenta de la centralidad del "agua" o podríamos decir el río en la vida isleña. Todo se organiza en torno a ésta, a la vez, que es algo arraigado, se hace cuerpoy permanece, en términos sociológicos, naturalizado tornándose consciente a partir de la reflexión, tensión o conflicto. Por otro lado, se despliegan una serie de saberes y técnicas necesarias para la vida cotidiana y relacionadas directamente con este elemento ecosistémico. Este aprendizaje por cuerpo (Bourdieu, 1980 y 1997) es resultado del contacto directo con el río, con el humedal, en la necesidad de, por ejemplo, bañarse, ir a la escuela y disfrutar del río en verano, etc. 0 bien, vinculado a saberes y técnicas como manejar un bote que puede ser enseñado y aprendido en la práctica misma y el conocer cómo es la dinámica del río.

En este sentido, para "vivir en la isla" es necesario conocer en términos prácticos un conjunto de variables directamente vinculadas al ambiente donde se realizan las actividades vitales. Además, suelen señalar en sus testimonios: "todo depende del tiempo", "de la marea" o "de la bajante", "de la luna":

"Acá el río te impone, si hay agua muy baja no podés salir, si hay sudestada agarrate que te lleva" (Jorge, 2010).

"Que el agua esté alta o baja depende de la luna, del viento. A la noche, si sopla viento norte fuerte, ya sabés que al otro día tenés un río bajo. Y si tenés un viento sur crece el agua...

... a veces, vos programas a la noche y al otro día, cuando te levantas, por ahí tenés el agua tocando el piso del rancho y no podés hacer nada..."

(Entrevista colectiva a isleños de la Cooperativa Isla Esperanza, 2010: publicado en "Isla Esperanza", 2013).

Estas maneras de expresión resultan muy interesantes para desmenuzar los sentidos que adquieren la vida en las islas y la relación con el río, constitutivos del "modo de vida isleño" o la "experiencia isleña". Tomando la frase "todo depende del tiempo", ésta refiere al tiempo en términos del clima, pero a la vez, del funcionamiento ecosistémico y a la temporalidad humana configurada en esa relación directa con la naturaleza. Es decir, una frase que condesa un tiempo-espacio-naturaleza-humanidad en-con las islas y el agua. Poéticamente, "Son tan lentos y constantes como el río".

Al precisar en esa experiencia señalan "Acá el río te impone". El agua del río termina por ser vivenciada en tanto determinante de la vida en las islas:

"Con el agua baja te queda burrear o esperar la creciente. Si el agua no crece, irte y volver a buscarlos cuando esté crecida. Si los mazos están en un lugar medio al reparo, te aguanta. Pero si hay mucha marejada los rompe. Son tres opciones, depende de cada islero. Si estás lejos, esperar el creciente o irte. O si estás cerca, acarrearlo para no volver a la madrugada."

(Entrevista colectiva a isleños de la Cooperativa Isla Esperanza, 2010: publicado en "Isla Esperanza", 2011).

Tal como dicen si el "agua está alta" o "baja" son las tareas vitales que pueden desarrollarse, más allá de la "programación" que pudo haberse realizado. También relatan que, para cada momento del río se pueden realizar diferentes tareas, con lo cual suele esperarse al momento adecuado, por ejemplo, para cortar junco el agua es mejor que esté baja, o para "clavar estacones o las patas del muelle." Y si está alta o hay marea "se aprovecha para mover los troncos grandes para leña"o "tirar la chata al río".

La experiencia directa de "imposición del río" se hace presente en otras escenas de la vida isleña, pese a que las casas son palafíticas para permitir el flujo del agua, hay inundaciones excepcionales que pueden "llevarse todo". Aquí "la marea" o "sudestada" cobra dimensión de fatalidad o catástrofe. Si bien son experiencias que marcan las historias de vida, les isleñes tienen en su bagaje experiencial histórico estas situaciones como una posibilidad, esto no lo conceptualizan como un riesgo temerario, ni viven con miedo, tienen la certeza de tener los conocimientos necesarios para "volver a levantar el rancho", "siempre nos arreglamos solos"y con la "solidaridad isleña". Respecto a las "mareas" periódicas:

Susana [isleña de "toda la vida"]: con los años esto de las mareas y va aflojando, quieras o no quieras, por mejor encadenamiento que tengas, fue trabajando y yéndose para atrás [la casa]. Pero bueno, yo ya estoy acostumbrada, 
a vivir así... no tiene arreglo. O sea se podría una empresa, pero lo que se puede llegar a cobrar...

\section{Sofía: te entra la marea en tú casa?}

Susana: Sí, yo estoy ambientada, eso no me asusta... en el momento porque obviamente levantar y bueno, saco barro, cada tanto hay que pintar, bueno, y así vivo. Mi hijo me dice: "Muy lindo, tanta marea, tanta cosa ¿no te acobarda?" No, no, nosotros seguimos. Yo te digo yo era chica en la casa de mi abuelo era levantarse muchas veces, viste que si bien la influencia del viento tiene que ver con la subida del agua pero muchas veces no había viento y el agua crecía. Los terrenos eran más bajos y era levantarte, llegar a la escalera y ver las cacerolas flotando, teníamos, nunca me voy a olvidar, un aparador divino provenzal, bueno ese vivió más abajo del agua que otra cosa.

\section{Sofía: y había que salir a buscarlo, claro}

Susana: había que convivir con eso, qué va a ser." (Susana, 2012)

Del relato de Susana me llamaron la atención varias frases: una es la aceptación de que "había que convivir con eso", no en términos de resignación sino de elección "con marea y todo me quedo abajo". Esa aceptación también es resultado de un conocimiento y una elección. Esta noción de que las casas y los muelles van "trabajando" es frecuentemente enunciado y refiere a que dadas las características lodosas del suelo y el estar en constante influencia del flujo del agua, las casas o los pilotes que las sostienen pueden moverse, generando en muchos casos una visible inclinación. A la vez da cuenta de que el agua, la tierra (barro, sedimentos) y la madera de los palafitos de las casas trabajan en conjunto. En otras palabras perciben el ecosistema, lo no-humano, y lo humano (sus casas, canales, etc.) como algo que interacciona o "va trabajando" en conjunto a lo largo del tiempo. No se perciben como elementos separados, sino interactuantes, co-existentes.

En sintonía, otra frase curiosa y fascinante es la de "yo ya estoy ambientada". Esta metáfora da cuenta, por un lado, de una manera de hacerse y ser en el espacio a la vez que de reconocerse como parte del ambiente en una relación de co-existencia: el ambiente la constituye y ella al ambiente.
Cada elemento "natural" es expresado y significado dentro de una gramática experiencial resultante de esa relación directa con el ecosistema, se percibe como una totalidad integrada donde la humanidad es/se hace parte. Lejos de ser una vínculo idílico, de fascinación por el paisaje, es una relación, al decir de Bartra (2011) turbulenta, o como escribiera Conti sobre estos isleños, "No aman al río exactamente, sino que no pueden vivir sin él."

Esta relación turbulenta también se enuncia en expresiones locales frecuentes como "el río se comió la chata", "el río se tragó el muelle". Se le atribuye cualidades o capacidades humanas al río, pero también a otros elementos como "el monte", tales como comer, avanzar, tragar, devorar. Esta interacción con los elementos naturales produce en cierto modo un deseo de "dominio" sobre "la naturaleza", para el caso del monte han aprendido a "mantener limpio"en las zonas necesarias para las actividades vitales dejando el pajonal sin intervención donde "el bichaje puede vivir". Aceptando el "avance fagocitante del monte", pero estableciendo ciertos límites frente al mismo, aluden a una relación de fuerza casi "cuerpo" a "cuerpo" con el monte. Para el caso del río, finalmente genera una suerte de resignación: cuando dicen "la naturaleza es implacable" o "el río te impone" se reconoce y percibe la fuerza que les impone el agua, aceptando que "todo depende del río".

Podemos interpretar estas maneras de enunciación y de significación en torno a la naturaleza como resultado de una modalidad de relación o articulación en la cual se adaptan a las singularidades ecosistémicas. Adaptación que no se ajusta al fatalismo moderno de la dualidad insoslayable, sino una aceptación elegida, pues han aprendido a realizar diferentes actividades vitales de acuerdo a las variables ecosistémicas y pese a las desavenencias que genera eligen vivir en las islas.

Otra afirmación que he registrado es la de: "a las islas las hicimos nosotros", "he visto crecer a las islas". Estas expresiones son más frecuentes en aquellas familias que reconocen la actividad de junquear como principal para su vida y sostenimiento económico-familiar. ${ }^{8}$ Respecto a esto señalaré brevemente que es una actividad productiva de recolección que se realiza principalmente en el frente de avance del delta. Como expresan en los fragmentos de entrevista, para realizar la actividad "dependen del tiempo", conocer, en términos prácticos, una serie de variables, elementos del ecosistema y

8. Para un acercamiento más profundo a la vida y sujetos aso- 
cómo funcionan en conjunto. Así, reconocen los procesos formadores de islas, entre los cuales se encuentra el juncal: la plantación de estacas de sauces en los juncales favorece la fijación más rápida de los sedimentos barrosos que carga el río. ${ }^{9}$ El resultado es que donde se plantan sauces u otros árboles "va creciendo la isla", la sedimentación se acelera y se van formando nuevas islas. Han aprendido también que luego de las mareas, el barro que queda va sedimentando y hace "crecer las islas". De allí la experiencia de hacerlas y verlas crecer, observan cómo con el correr de los años van dejando de ser río para ser islas.

Llegan a percibirse como productores del paisaje que los rodea, y, por ende, su existencia aparece enunciada como una mutua determinación con el ecosistema, tanto porque este los condiciona, como porque su acción es constitutiva del ambiente (islas, canales, arroyos navegables, monte, arboledas del albardón, secado del centro de isla, etc.). En la observación contemplativa de "verlas crecer"lo enuncian en términos co-constitutivos, crecen juntes (Astelarra y Domínguez, 2015).

Por último, en estas maneras de apropiarse de las islas y el río las áreas de vivienda o de producción (pesca, junco) no se definen necesariamente en términos de propiedad privada, sino en tanto uso socialmente necesario para las actividades vitales de la organización familiar o individual. En este sentido, Ferrero (2012) señala sobre la gestión comunitaria de la pesca en el Bajo Delta del Paraná que: "en la gestión que los pescadores hacen del río es central considerarlo como un espacio libre y abierto. El río es visto por los pescadores como un espacio sin dueño, sobre el que todos tienen iguales derechos, sin restricciones a su acceso y circulación" (Ferrero, 2012: 73).

Esta percepción respecto al río se extiende al uso común de los juncales, las costas, canales, arroyos e incluso de algunos montes de los cuales extraer madera. Coincidiendo con Ferrero, "En el caso del bajo Paraná, por décadas, se desarrolló una modalidad particular de gestión de los recursos naturales basada en relaciones comunitarias" (Ferrero, 2012: 63). Entonces, lo que caracteriza este modo de apropiación del espacio para la vida, es que la organización del territorio está dada por una "gestión comunitaria" o lógica social comunitaria

$\overline{\text { ciados a la actividad junquera ver: Astelarra y Domínguez, } 2014 .}$

9. El junco es el primer ambiente formador de islas en esta zona de frente de avance. de uso del mismo en función de las necesidades vitales, las dinámicas ecosistémicas y el respeto a esos códigos de uso y costumbre. Podríamos decir que el río, arroyos y canales, así como los juncales son percibidos y usados en tanto bienes comunes. Esta práctica, no va acompañada de un discurso de reconocimiento del uso comunal históricamente realizado en las islas, éste emerge en las últimas décadas como resultado de diferentes conflictos por su apropiación y significación.

Finalmente, es menester mencionar, aunque brevemente, que en las últimas décadas las islas han sido repobladas, muchas de estas personas "venidas" buscaban "un refugio" o "cambiar la vida" urbana por otra "en contacto con la naturaleza". Con el tiempo, en experiencia directa con el ecosistema, por ejemplo, en "las grandes mareas":

"No sabía qué hacer, creí que me iba a morir ahogado. Hasta que vino un vecino en canoa y me dijo que estaba todo bien. jJajaja! [...] Al principio hice todo mal: llegué y corté todo, hice el parque como hacen los del fin de semana, viste. Y veía a los isleños que cortaban cerca de la casa y un poco a los alrededores y nada más, pensaba "son unos vagos estos". Claro yo venía con la cabeza de la ciudad. Después entendí, que ellos le dejan lugar al bichaje." (Jorge, 2013)

En su llegada al Delta, expresaban un vínculo idílico con las islas y el río, luego en la interacción con el ecosistema se encontraron con las turbulencias, los miedos e incertidumbres. Tuvieron que "sacarse la ciudad de la cabeza" para poder relacionarse con el río, el monte, el "bichaje", adaptarse a su funcionamiento. En la interacción con las familias isleñas "de toda la vida", aprendieron algunos usos del espacio para realizar sus actividades vitales (zanjeo, construcción, etc.) y permitir el funcionamiento del ecosistema.

En la década de los ochenta, algunos percibieron el cambio en la coloración y el olor en el agua y luego la aparición de grandes cantidades de peces muertos. Por aquel entonces, aún tomaban agua del río haciéndola decantar con filtros de barro, de modo que esta situación se tornaba de vital importancia. A partir de la mortalidad de peces y de sus investigaciones, determinan que se trata de contaminación industrial. Lo definen como problema ambiental dando inicio al movimiento ambiental en Tigre (Ronis, 2013). Surge una nueva narrativa local asociada a otras significaciones de las islas y los ríos, por momentos cuestionando aquello 
percibido como "natural" por "los de toda la vida", ocasionando rispideces así como también encuentros y acciones colectivas para mejorar y defender la vida isleña. En 2016 circuló por los medios de comunicación local:

"Ríos que matamos, iiMATAN!!. Río Reconquista: 40 años de incumplimiento, endeudamiento y contaminación: [subrayado del original] Hace 40 años que vivo en el Delta y cruzo al menos 2 veces por día el Río Luján. Soy un observador de los cambios negativos que sufre el agua, que impacta en la vida subacuática y de quienes habitamos la región. [...] Una funcionaria del OPDS (Organismo Provincial de Desarrollo Sostenible) manifestó -con power point incluido- que con una "Escala de Indicadores Cromáticos "que miden la contaminación - (metodología canadiense) se observaba con color verde una mejoría en la calidad de agua del Canal Aliviador.

Yo había navegado esa zona días antes, verificando todo lo contrario. La respuesta de un correo electrónico a la controversia, es que ellos han verificado que alli hay tortugas, anguilas y peces; prueba biológica de que allí hay vida.

Quiero evitar adjetivaciones. Es cierto que hay tortugas en el Reconquista Chico. Habría que investigar sobre adaptaciones y/o mutaciones y eventualmente muertes. Las anguilas han desaparecido en esta zona como especie, además de otros peces como la vieja del agua, el patí, surubí, y otros. Y los peces que dicen que han visto, -si los vieron- (en el río, por el color del agua no se ven los peces) es que están muriendo. Y eso explica que estando en superficie, haya cantidad de aves que con más comodidad aprovechan esta circunstancia para alimentarse. Los peces cuando el agua está en mejores condiciones por el ingreso del río de la Plata, entran en los Ríos Tigre, Reconquista Chico y Aliviador, quedando atrapados luego en la contaminación cuando el agua comienza a bajar. Ahí es cuando se los ve en superficie buscando oxígeno, produciéndose las muertes masivas que tantas veces hemos denunciado." (Carta Pública, Martín Nunziata, Delta de Tigre, 17 de Octubre de 2016)

Esta carta da cuenta de otro momento de la memoria del río, la historia reciente del cambio en la composición del agua o de su contaminación a índices que sobrepasan la capacidad de resiliencia del ecosistema alterando su funcionamiento y vitalidad. Esta noción de "ríos que matamos" da cuenta de las actividades humanas nocivas y mortíferas que se vuelven contra la propia humanidad y nos "matan". La carta denuncia la complicidad y el accionar gubernamental que alimentan ese círculo mortal con diagnósticos tecnocráticos y falaces.

Nuevamente, enuncia esa articulación entre lo biológico y lo histórico, en su fase destructiva. A la par que se visibiliza otro tipo de conocimiento local que han generado quienes se han venido a vivir a las islas, que también parte de la percepción y experiencia vital directa con el ecosistema, sumado a investigaciones propias que mixturan con el saber experto, dialogando con la forma argumental moderna y científica. Este modo de enunciación se ha forjado en las diferentes disputas locales generadas a partir de la construcción del ambientalismo local, donde aprendieron a legitimar y validar sus argumentaciones para denunciar las transformaciones locales, los impactos ambientales y sociales, así como presionar a organismos gubernamentales para intervenir en estos asuntos. Como mencionamos, uno de esos conflictos es "Colony Park", su potencialidad residió en el encuentro de las familias isleñas históricas y el movimiento ambiental local, integrado mayoritariamente por venides. Se generó una mirada y significaciones en común instalando en la escena pública las nociones de modo de vida isleño y humedal, a la vez que visibilizando estos distintos sujetos y la relación con el río, las islas.

\section{Conclusiones}

"Cada una de estas grandes arterias del movimiento visible de las aguas y de la tierra, es un largo drama de luchas, de despojos y de conquista". (Sarmiento [1857], 2011: 52)

Sarmiento mientras señalaba eso, acuñaba el significado del Delta como la Venecia Argentina, instaurando no sólo esa imagen, sino el primer modelo "exitoso" de desarrollo de producción frutihortícola, inmigración y colonización de las islas cuyo destino era asemejarse a un estilo dominante eurocéntrico de la época. Y aquella imagen se actualiza en el presente con el modelo americanizado Miami-Dubai que impulsa el desarrollo inmobiliario-financiero en una nueva fase de despojo y colonización que viene a "urbanizar el río". 
Esta modalidad de articulación de lo biológico y lo histórico asociada a la modernización ecológica y ecoeficiencia amerita un artículo completo, solo menciono que, desde la década de los noventa se proyecta la "urbanización del río" asociada a la construcción de barrios cerrados acuáticos en el delta destinados a segunda residencia de sectores de altos ingresos o bien para la especulación económica. Este proceso transforma el paisaje isleño, el funcionamiento ecosistémico y promueve "olvidarse de todo"(Astelarra, 2016). Tal ha sido el mencionado caso "Colony Park" que se proyectaba entre otros ríos, sobre el Arroyo Anguilas- pese a ser arroyo es tratado como río- para lo cual fue transformado drásticamente y sus habitantes desalojados violentamente.

Conti inicia "Sudeste" con una hermosa descripción de este arroyo que hoy ya no existe tal cual era, aquel río queda en la memoria de sus habitantes y visitantes, que actualizan en el presente su elección de vivir en ese territorio. Desde su colonización la memoria del río viene cargada de conflictos.

En este trabajo hemos desplegado algunos aspectos de esta memoria del agua o el río y el río en la memoria, específicamente los modos de uso, de significación y los conocimientos locales. Recorrimos una pluralidad de significaciones y apropiaciones respecto al agua/ río, en tanto uso vital como recurso para vivir y producir (pesca o junco), de traslado; en tanto elemento natural que dada su fuerza se impone o condiciona la vida humana (ritmo del trabajo, actividades vitales) incluso llegando a experimentar la fatalidad que puede ocasionar esa fuerza del río (pérdida de sus casas, embarcaciones, etc.). En tanto bien común, el río y por ende las áreas de juncales e islas en formación (donde el agua y la tierra aún no se diferencian) no se conciben en tanto propiedad privada, son percibidas como propiedad común de uso y disfrute social.

Otro aspecto es el aprendizaje y conocimiento con/del río. En algunos testimonios observamos que el lenguaje local no se expresa en terminología técnica o científica, sino como parte de una gramática de la experiencia vital, que el "monte se devore todo", o que el río "avance comiéndose" tal objeto, o "se llevó todo" da cuenta del conocimiento incorporado respecto a ese crecimiento veloz y el funcionamiento dinámico del ecosistema. Conocimiento requerido para las actividades vitales y productivas sin los cuales no podrían vivir. De allí que, ante la "programación" de sus actividades saben que "todo depende del tiempo".
Con los años y en los conflictos sociales, estos conocimientos de "los isleños de toda la vida"se mixturan con investigaciones locales de "los venidos" instalándose entre muchas- las nociones de humedal y cuenca como claves para re-interpretar los espacios vitales, el funcionamiento del río y las islas.

Estos grupos sociales mencionan una relación de contemplación cotidiana del río, este enseña a habitarlo y disfrutarlo. Así, tienen en común que han generado una particular relación con el humedal, han ido tejiendo un "modo de vida isleño" en el cual se constituye una subjetividad isleña asociada a esa vida en permanente contacto con el río, el monte, las islas, etc. En esta adaptación- a las potencialidades y limitantes- e intervención, se generan saberes asociados al reconocimiento del funcionamiento del ecosistema que son vital para su existencia. A la vez que, técnicas de manejo que garantizan la realización de las actividades vitales sin interrumpir completamente el funcionamiento dinámico del ecosistema, como vimos, con el flujo del agua.

Estos saberes prácticos son, en términos de Bourdieu (1980 y 1997), un aprendizaje o conocimiento por el cuerpo. El contacto experiencial, cotidiano e histórico con el ecosistema produce un saber respecto del mismo que no se expresa en los términos académicos o técnicos sino en un lenguaje de valoración local resultado de esa relación histórica con el ecosistema. Es decir, el sujeto existe en el mundo, habita el mundo corporalmente, las herramientas que construye para comprenderlo práctica y teóricamente son dadas por el mundo, a la vez que son transformadas en y por el mundo. Es, en el cuerpo, donde reside la potencialidad, la "capacidad para", refiriendo al movimiento corporal como la capacidad de dar sentido, de comprender intelectualmente y en sentido práctico, es una potencia para la acción dentro de condicionantes históricos (Bourdieu, 1980 y 1997). Entonces, el lenguaje de valoración local, los sentidos y significaciones registrables en las expresiones o maneras de referirse a su mundo de vida, dan cuenta de la articulación de lo biológico y lo histórico, por ende, del río en la memoria y las memorias del río.

Estos "conocimientos por cuerpo" (Bourdieu, 1980 y 1997), en tanto gramática de la experiencia vital-cultural, van construyendo históricamente un conocimiento local (Escobar, 2000). Escobar lo define dentro de:

"Los modelos de cultura y conocimiento se basan en procesos históricos, lingüísticos y 
culturales, que, aunque nunca están aislados de las historias más amplias, sin embargo retienen cierta especificidad de lugar. Muchos de los aspectos del mundo natural se colocan en lugares. Además, muchos de los mecanismos y prácticas en juego en las construcciones de naturaleza -linderos, clarificaciones, representaciones, aprehensiones cognitivas y relaciones espaciales- son significativamente específicas de lugar." (Escobar, 2000: 54)

Estos conocimientos locales, refieren a unas construcciones de naturaleza (Escobar, 2000) o a la significación social de la naturaleza, (Leff, E. 2006) enraizada en los lugares. La hechura del lugar, en tanto creación del espacio propio se produce a lo largo del tiempo, en tanto resultante de la articulación de la historia y lo biológico.
Procuré rastrear pistas para comprender la articulación singular del modo de vida isleñe que tiene de distintivo que las personas se imbrican, mixturan, entretejen en una experiencia de ser parte del río, "son del todo semejantes a él" escribe Conti; un sentipensar el río interconectados a éste, co-existente.

Para cerrar, volviendo a Conti "el río teje su historia y uno es apenas un hilo que se entrelaza con otros diez mil". De allí que señalar que "el río es memoria" en el Bajo Delta del Paraná significa necesariamente cartografiar la articulación humanidad-naturaleza, rastrear en la historia larga y del presente cómo lo biológico y lo histórico han interactuado o interconectado dejando huellas en el espacio, en los nombres y sus usos, o bien, arraigadas en las personas, sus experiencias y relatos.

\section{Bibliografía}

Astelarra, S. (2016) "Disputas por la reinvención del "paraíso deltáico": de los lugares de la querencia a llegar a una isla y olvidarse de todo. El caso del conflicto "Colony Park" en la Primer sección de Islas del Delta del Paraná". En Merlinsky Gabriela coord. "Cartografías del Conflicto Ambiental en Argentina II", Ciudad Autónoma de Buenos Aires, Fundación CICCUS.

Astelarra, S. y Domínguez D. (2015), "Los junqueros de las islas del Delta del Paraná: sujetos emergentes en un territorio amenazado". Estudios Socioterritoriales. Revista de Geografía, No 17, pp. $129-162$ [en línea], Recuperado: URL: http://revistaest.wix.com/revistaestcig\#!n-17--enero-junio-2015/cfee.

Astelarra, S., Domínguez, D. y de la cal, V. (2017). "Conflictos en los Sitios Ramsar de Argentina: aportes para una ecología política de los humedales". "Letras Verdes. Revista Lationamericana de estudios socioambientales", FLACSO Sede Ecuador, ISSN 1390-6631. DOI: https://doi.org/10.17141/letrasverdes.22.2017.2689.

Bourdieu P. (1991 [1980]). El sentido práctico, Capítulos 3, 4 y 5, Madrid, Taurus.

Bourdieu P. (1999 [1997]). Meditaciones Pascalianas, Puntos 4 y 5, Barcelona, Anagrama.

Conti, H. (2010 [1962]), Sudeste, Buenos Aires, Emecé.

Cooperativa de Junqueros Isla Esperanza (2013), Isla Esperanza. Trabajo, naturaleza y resistencia isleña, Buenos Aires, Instituto Nacional de Asociativismo y Economía Social (INAES).

Escobar, A (1999), "El mundo pos natural: elementos para una ecología política antiesencialista”, en El final del salvaje [pp. 273-315], Bogotá, CEREC - ICAN -Giro Editores.

Escobar, A (2000), "El lugar de la naturaleza y la naturaleza del lugar: ¿globalización o postdesarrollo?". En Lander, E. (comp.), La colonialidad del saber: eurocentrismo y ciencias sociales. Perspectivas Latinoamericanas [pp. 113143], Buenos Aires, CLACSO.

Ferrero, B. (2012), "La gestión comunitaria de la pesca en el bajo Paraná argentino. Un estudio de caso con pescadores artesanales". En Alcalá, Graciela, y Camargo

Alejandro (eds.) Pescadores en América Latina y el Caribe: espacio, población, producción y política, Ciudad de México, Ed del Centro Interdisciplinario de Investigaciones en Medio Ambiente.

Galafassi, G: (2005), Pampeanización del Delta, Buenos Aires, Extramuros.

Kalesnik, Fabio (1997), Relación entre las especies exóticas y la heterogeneidad ambiental a nivel regional en el Bajo Delta del Río Paraná, Informe final, Beca de Iniciación, Facultad de Ciencias Exactas y Naturales, Universidad de Buenos Aires, Buenos Aires. 
Kalesnik, F. y Quintana, R. (2006) "El delta del río Paraná como un mosaico de humedales. Caso de estudio: "la reserva de biosfera MAB-UNESCO: Delta del Paraná." En Revista UnG - Geociências V.5, N.1, 22-37., Buenos Aires.

Kandus, P. (1997), Análisis de patrones de vegetación a escala regional en las islas del sector bonaerense del Delta de Río Paraná, Tesis Doctoral, Universidad de Buenos Aires, Buenos Aires.

Leff, E. (2006), "La ecología política en América Latina. Un campo en Construcción”. En Alimonda, H. (comp.), Los tormentos de la materia Aportes para una ecología política latinoamericana [pp. 219-229], Buenos Aires, CLACSO.

Leff, E. (2014), La apuesta por la vida, Buenos Aires, Siglo XXI.

Malvárez A. (1999) "El delta del rio Paraná como mosaico de humedales". En libro Tópicos sobre humedales subtropicales y templados de Sudamerica, Montevideo, Uruguay. Oficina Regional de Ciencia y Tecnología de la UNESCO para América Latina y el Caribe-ORCYT.

Muscillo G. (2016) La Terrible y Ejemplar Historia de Marica Rivero, Alias La Malparida, sin datos, Recuperado: http:// independent.academia.edu/GabrielMuscillo

Paschkes Ronis, M. (2013), "El Delta en disputa. Conflictos y controversias ambientales en el partido de Tigre". En Merlinsky, G. (comp.), Cartografías del conflicto ambiental en Argentina [pp. 143-170], Buenos Aires, CICCUS.

Sarmiento D.F. [1857], (2011), El Carapachay, Buenos Aires, Eudeba. 